\title{
PENILAIAN TATA KELOLA TEKNOLOGI INFORMASI UNIVERSITAS TANJUNGPURA MENGGUNAKAN COBIT 5 DOMAIN ALIGN, PLAN, DAN ORGANISE (APO)
}

\author{
Nurul Mutiah \\ Universitas Tanjungpura \\ Jalan Prof. Dr. H. Hadari Nawawi Pontianak, 78124 Indonesia \\ nurul@sisfo.untan.ac.id
}

\begin{abstract}
Abstrak-Tata kelola TI bagi Universitas membantu dalam proses tercapainya strategi universitas. COBIT 5 memiliki Process Reference Model yang terdiri atas domain EDM, APO, BAI, DSS, dan MEA. Untuk mengukur tata kelola TI Universitas Tanjungpura dalam hal pengelolaan manajemen dan strategi TI maka digunakan proses COBIT 5 yang berada pada domain APO yaitu APO 01 dan APO 02. Untuk melakukan penilaian maka ketiga proses tersebut dipetakan kedalam COBIT Process Assessment Model (PAM). Hasil penilaian tata kelola TI menyatakan bahwa Universitas Tanjungpura berada pada level kapabilitas 0 . Hal ini dikarenakan dengan tidak tercapainya persyaratan Largerly atau Fully Achieved pada seluruh proses APO yang dinilai. Hasil penilaian kemudian digunakan sebagai acuan analisis Critical Success Factor, Key Goal Indicators, dan Key Performance Indicator yang dapat digunakan sebagai panduan bagi Universitas Tanjungpura untuk memperbaiki tata kelola TI khususnya pada pengelolaan manajemen dan strategi $T I$.
\end{abstract}

\section{Kata Kunci- Tata kelola TI, kapabilitas proses TI, Cobit 5, Cobit PAM}

\section{PENDAHULUAN}

Pengelolaan TI yang baik oleh sebuah organisasi dapat memberikan manfaat yakni efisiensi dan efektifitas dalam pelaksanaan proses bisnis organisasi. Pengelolaan TI merupakan sebuah upaya untuk meningkatkan kinerja organisasi dan merupakan tanggung jawab dewan direksi dan manajer eksekutif organisasi. Dalam membantu memenuhi kewajiban dewan direksi sehubungan dengan penggunaan TI untuk mencapai tujuan bisnis dalam organisasi maka diperlukan tata kelola TI. Menurut ISO/ IEC 38500 Tata Kelola TI Perusahaan (corporate governance of information technology) adalah sistem dimana penggunaan TI saat ini dan masa depan diarahkan dan dikontrol [1]. Tata kelola TI perusahaan meliputi evaluasi dan mengarahkan penggunaan TI untuk mendukung organisasi dan memonitor penggunaannya dalam rangka mencapai apa yang direncanakan. COBIT (Control Objectiffor Information and Related Technology) 5 merupakan sebuah kerangka kerja standar internasional yang dapat digunakan oleh organisasi dalam melakukan tata kelola TI dan menilai level kapabilitas tata kelola TI organisasi. COBIT 5 memiliki Process Reference Model yang terdiri atas domain EDM, APO, BAI, DSS, dan MEA dan terdiri atas kumpulan dari 37 proses tata kelola dan manajemen TI [2].

Universitas Tanjungpura sebagai institusi perguruan tinggi memanfaatkan TI untuk mendukung tercapainya strategi universitas. Dengan demikian Universitas Tanjungpura telah melakukan investasi TI dalam rangka mendukung proses bisnis organisasinya. Penerapan TI memiliki investasi tinggi dalam pelaksanaannya, oleh karena itu diperlukan pengelolaan manajemen dan strategi TI yang tepat dalam mendukung tujuan organisasi. COBIT 5 dapat digunakan sebagai kerangka kerja bagi Universitas Tanjungpura dalam menciptakan nilai penggunaan TI yang optimal, meminimalisir resiko TI, dan meningkatkan efektifitas penggunaan sumber daya TI. Pada COBIT 5 terdapat domain APO (Align, Plan, dan Organise) khususnya APO 01 (Manage the IT Management Framework) dan APO 02 (Manage Strategy) yang dipilih sesuai dengan tujuan penelitian yakni menilai Pengelolaan Manajemen dan Strategi TI serta kesesuaian penggunaannya untuk mencapai tujuan organisasi. Penelitian ini mengemukakan penilaian level kapabilitas tata kelola TI Universitas Tanjungpura berdasarkan domain APO pada COBIT 5 serta memberikan panduan perbaikan tata kelola TI melalui analisis Critical Success Factor, Key Goal Indicator dan Key Performance Indicator yang sesuai dengan karakteristik dan keadaan Universitas Tanjungpura.

\section{STUDI LITERATUR}

Menurut IT Governance Institute (ITGI), tata kelola TI adalah tanggung jawab dewan direksi dan manajemen eksekutif, hal ini merupakan bagian yang tidak bisa dipisahkan dari tata kelola perusahaan yang terdiri dari kepemimpinan, struktur organisasi serta proses yang memastikan bahwa organisasi TI mendukung dan memperluas strategi dan tujuan 
organisasi [3]. COBIT 5 merupakan kerangka kerja tata kelola TI yang dikembangkan oleh ISACA, meliputi proses tata kelola dan proses manajemen sebagai area kunci dalam modelnya [4]. COBIT 5 menyediakan praktek terbaik dalam mempresentasikan framework mengenai domain dan proses dengan pengelolaan yang baik dan terstruktur. COBIT lebih berfokus pada pengendalian (kontrol) dibanding hasil. Framework pengontrolan COBIT diperlukan dalam rangka [5]:

a. Membuat hubungan dengan persyaratan bisnis

b. Mengorganisir aktivitas TI kedalam model proses yang dapat diterima

c. Mengidentifikasi sumber daya TI agar dapat diberdayakan

d. Menemukan sasaran pengendalian manajemen agar dapat dipertimbangkan .

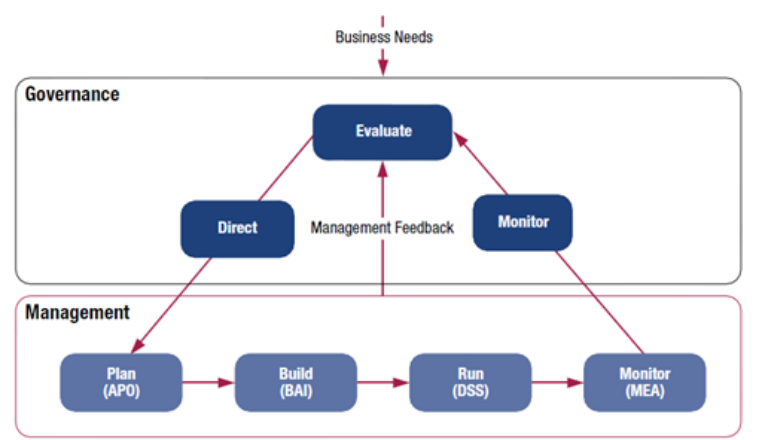

Gbr 1. Konteks Diagram Sistem

COBIT 5 memiliki Process Reference Model yang terdiri atas domain EDM, APO, BAI, DSS, dan MEA. Process Reference Model merepresentasikan seluruh proses terkait aktifitas TI organisasi. Domain mendeskripsikan strategi dan taktik dari praktek terbaik TI yang dilakukan dalam mendukung tujuan organisasi. Domain APO terbagi atas 13 proses mulai dari APO 01 hingga APO 13 [2].

Pada COBIT 5 terdapat dua level sasaran dan metric yaitu sasaran dan metric enterprise dan sasaran dan metric TI dimana pencapaian dari sasaran enterprise memerlukan sejumlah outcome terkait TI yang direpresentasikan oleh sasaran TI [6]. Terdapat dua indicator yaitu KPI (Key Performance Indicator) dan KGI (Key Goal Indicator) yang dapat dijadikan sebagai metric pada sasaran enterprise dan sasaran TI. KPI dan KGI muncul pada tiga level yaitu level proses, level enterprise dan level TI (Gambar 2), dimana KPI merupakan pendorong bagi KGI. Sedangkan CSF (Critical Success Factor) pada penelitian ini didapat dari analisis gap antara level kapabilitas saat ini dan level kapabilitas yang diharapkan. CSF merupakan rekomendasi yang harus dilakukan jika pihak organisasi menginginkan perubahan level pada tata kelola TI yang dimilikinya saat ini.

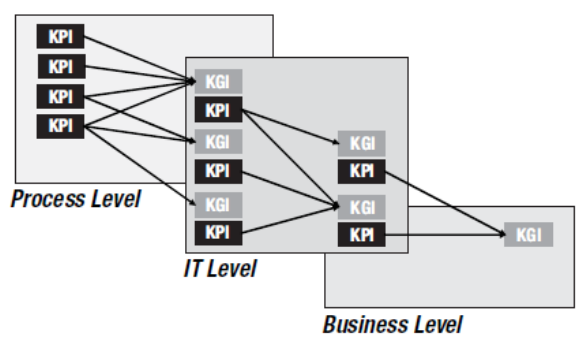

Gbr 2 KPI merupakan pendorong KGI [6]

Process Assessment Model (PAM) telah dikembangkan oleh ISACA (2011) [7] untuk mengatasi kebutuhan penilaian COBIT berbasis proses dalam rangka meningkatkan ketelitian dan keandalan penilaian proses TI. Model berfungsi sebagai dokumen acuan dasar untuk kinerja penilaian kapabilitas proses TI organisasi. Dimensi capability pada COBIT PAM menyediakan sebuah penilaian proses capability untuk memenuhi tujuan organisasi saat ini atau proyek bisnis untuk proses (Gambar 3).

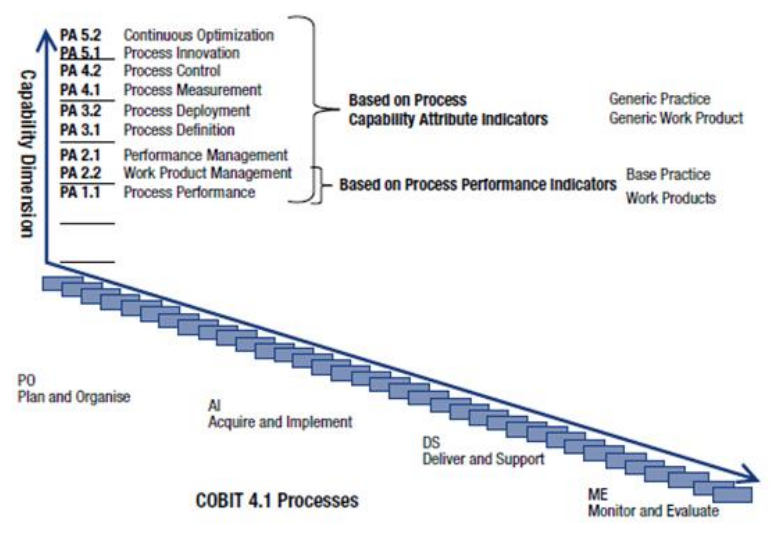

Gbr 3. Indikator Penilaian [7]

Indikator digunakan untuk menilai apakah atribut proses dapat diraih. Terdapat dua tipe indikator penilaian [7] :

1. Indikator kapabilitas proses, dengan tingkatan kapabilitas 1 sampai 5. Indikator ini bersifat umum untuk masing-masing atribut kapabilitas proses. Indikator yang digunakan untuk menilai kapabilitas proses adalah Generic Practice (GP) dan Generic Work Products (GWP)

2. Indikator kinerja proses, yang berlaku secara eksklusif untuk tingkat kapabilitas 1. Indikator kinerja proses (base practices dan work products) dispesifikasikan untuk masing-masing proses dan digunakan untuk menentukan apakah kapabilitas proses tersebut berada pada tingkatan 1 .

Setiap atribut dinilai menggunakan skala penilaian standar berdasarkan standar ISO/ IEC 15504 [7] yaitu: $\mathrm{N}$ Not achieved -0 to $15 \%$ achievement 
P Partially achieved $\longrightarrow 15 \%$ to $50 \%$ achievement

L Largely achieved $\longrightarrow 50 \%$ to $85 \%$ achievement

F Fully achieved $\longrightarrow 85 \%$ to $100 \%$ achievement

Capability level dari proses ditentukan oleh apakah process atribute pada tingkat yang telah banyak dan

Page | 67 sepenuhnya tercapai (largely and fully achieved) dan apakah atribut proses untuk tingkat yang lebih rendah telah sepenuhnya tercapai (fully achieved). Gambar 4 menguraikan setiap level dan peringkat yang diperlukan dan harus dicapai.

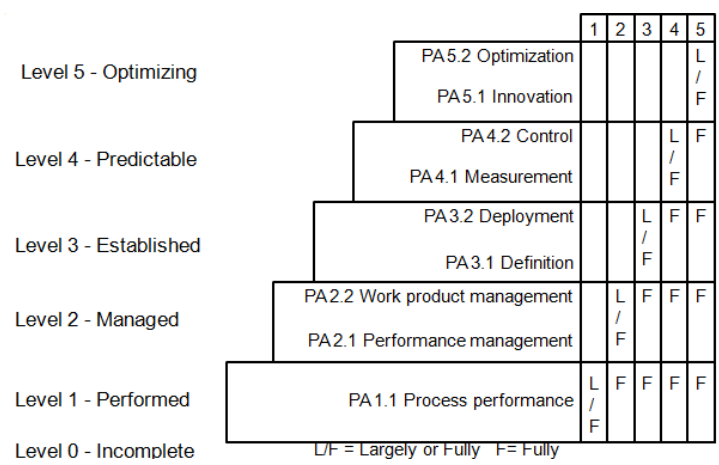

Gbr 4. Rating proses Atribut dan level kapabilitas PAM [7]

\section{METODOLOGI PENELITIAN}

Pengumpulan data pada penelitian ini dilakukan dengan menggunakan metode analisis data deskriptif kualitatif. Berfokus pada pengumbulan sumber data dan fakta dari sumber data utama yaitu melalui wawancara, observasi, dan kuisoner dan dari data pendukung berupa studi pustaka terhadap literatur yang sesuai.

Tahapan yang digunakan untuk menyelesaikan penelitian ini, yaitu:

1. Tahap Inisiasi Penilaian

Melakukan pemetaan domain APO COBIT 5, khususnya APO01, APO02, dan APO09 kedalam PAM sehingga didapat kerangka pengukuruan kapabilitas tata kelola TI beserta kuisoner penilaian.

2. Tahap Pengumpulan Data

Melakukan observasi, wawancara, dan kuisoner kepada stakeholder di Puskom Universitas Tanjungpura mengenai implementasi tata kelola TI yang ada sehingga didapat data dan informasi yang diperlukan dalam melakukan penilaian.

3. Tahap Penilaian

Melakukan analisis data yang telah didapat dengan menggunakan kerangka pengukuran kapabilitas tata kelola TI sehingga didapat level kapabilitas tata kelola TI Universitas Tanjungpura.
4. Tahap Analiaia Gap

Melakukan analisis gap implementasi tata kelola yang terjadi berdasarkan hasil yang didapat pada tahap penilaian dan harapan dari para stakeholder.

5. Tahap Perencanaan Rekomendasi.

Memberikan rekomendasi tata kelola TI kepada Universitas Tanjungpura dalam hal implementasi tujuan, kebijakan, strategi, dan layanan TI untuk mencapai tujuan organisasi dalam bentuk CSF, KGI, dan KPI.

\section{PEMBAHASAN PEMETAAN PROSES COBIT 5 KE PROCESS ASSESSMENT MODEL}

Process COBIT 5 didefinisikan sebagai process performance indicator yang dikenal sebagai process dimension dari process assessment model. Proses didalam process dimension dapat secara langsung dipetakan ke proses yang didefinisikan didalam process reference model.

Proses individu dijelaskan didalam nama proses, tujuan, outcome berdasarkan COBIT 5. Process dimension dari process assessment model memberikan informasi dalam bentuk:

1. Kumpulan dari base practice (BP) dari proses, memberikan sebuah definisi dari tugas dan aktifitas yang diperlukan untuk mencapai tujuan proses dan memenuhi hasil akhir proses. Setiap BP secara eksplisit dikaitkan kepada process outcome.

2. Sejumlah input dan output dari work product (WP) dikaitkan dengan setiap proses dan terkait pada satu atau lebih dari hasil akhirnya.

3. Karakteristik yang dikaitkan dengan setiap WP

Berdasarkan penjelasan diatas, maka pemetaan proses COBIT 5 khususnya APO 01 dan APO 02 dapat dilihat pada Tabel 1 berikut.

TABEL I

HASIL PEMETAAN PROSES APO 01 DAN APO 02

\begin{tabular}{|c|c|c|}
\hline $\begin{array}{c}\text { Proses } \\
\text { COBIT 5 }\end{array}$ & Jumlah BP & Jumlah WP \\
\hline APO 01 & 16 & 16 \\
\hline APO 02 & 12 & 12 \\
\hline
\end{tabular}

\section{PENILAIAN TATA KELOLA TI UNIVERSITAS TANJUNG PURA}

Dari wawancara dan kuesioner yang diberikan kepada pihak Puskom Universitas Tanjungpura tentang kapabilitas proses tata kelola TI di Universitas Tanjungpura diperoleh hasil penilaian untuk proses 
Align, Plan and Organise (PO) dapat dilihat pada Tabel 2 dibawah ini.

TABEL II PERHITUNGAN KUESIONER TINGKAT KAPABILITAS

Page | 68

\begin{tabular}{|c|c|c|c|c|c|c|}
\hline & \multicolumn{2}{|c|}{ Base Practice } & \multicolumn{2}{|c|}{ Work Product } & \multirow{2}{*}{ Total } & \multirow{2}{*}{ Ket. } \\
\hline & Ada & Tidak & Ada & Tidak & & \\
\hline $\begin{array}{c}\text { APO } \\
01\end{array}$ & 2 & 14 & 11 & 5 & $41 \%$ & $\begin{array}{l}\text { Partially } \\
\text { achieved }\end{array}$ \\
\hline $\begin{array}{c}\text { APO } \\
02\end{array}$ & 4 & 8 & 5 & 7 & $\begin{array}{c}37.5 \\
\%\end{array}$ & $\begin{array}{l}\text { Partially } \\
\text { achieved }\end{array}$ \\
\hline
\end{tabular}

Dari hasil perhitungan kuiseoner pada Tabel 2 menunjukkan terdapat 2 proses Partially achieved. Dengan demikian, dapat disimpulkan bahwa proses Align, Plan and Organise (PO) berada pada level 0, karena kedua proses yakni APO 01 dan APO 02 tidak mencapai tingkat Largelly achieved atau Fully achieved.

\section{PENENTUAN CSF, KGI, KPI}

Berdasarkan hasil pengukuran tingkat kapabilitas proses tata kelola TI pada Universitas Tanjungpura maka didapat keadaan awal yang masih berada pada level 0. Terdapat harapan dan target dari pihak organisasi untuk naik 1 level dari level saat ini. Dengan demikian terdapat gap yang harus dipenuhi oleh Universitas Tanjungpura agar dapat mencapai level 1 ddalam melakukan tata kelola TI. Untuk mengatasi gap ini maka penelitian ini memberikan rekomendasi berupa acuan dan indicator melalui critical success factor (CSF), key goal indicator (KGI) dan key performance indicator (KPI) yang dapat diterapkan oleh Universitas Tanjungpura.

\section{A. $C S F$}

\section{CSF untuk APO 01}

- Struktur oganisasi TI internal mencerminkan kebutuhan bisnis dan TI, sehingga mendukung pembuatan keputusan yang efektif dan efisien.

- Praktek pengawasan yang memastikan bahwa peran dan tanggungjawab dari seluruh personel organisasi terkait TI telah dilaksanakan, mencakup proses penilaian kinerja.

- Kebijakan TI mempertimbangkan faktor resiko, tujuan perusahaan (visi, arah, strategi), prinsip bisnis, dikembangkan untuk mengendalikan ekspektasi pengendalian TI.

- Pengkomunikasian informasi arah dan tujuan TI dengan level rincian informasi yang tepat untuk masing-masing stakeholder.

- Evaluasi organisasi TI dengan mempertimbangkan fungsi TI, strategi dan model organisasi perusahaan, situasi organisasi.

- Pedoman klasifikasi data tepat dan konsisten.
- Pedoman keamanan dan pengendalian data dan informasi yang efektif.

- Prosedur pengelolaan integritas dan konsistensi pengelolaan informasi pada repository.

CSF untuk APO 02

- Dipahaminya tujuan dan strategi perusahaan, lingkungan internal dan eksternal perusahaan, stakeholder dan kebutuhannya serta sumber perubahan dan memastikan peluang untuk perubahan strategi perusahaan.

- Identifikasi data bisnis dan TI, kapabilitas dan layanan TI serta identifikasi resiko dari potensi dan penurunan teknologi saat ini.

- Sasaran TI level atas berkontribusi terhadap tujuan bisnis perusahaan.

- Pendeskripsian arsitektur perusahaan, proses dan prosedur bisnis dan TI, struktur organisasi TI, penyedia layanan TI, tata kelola TI, kompetensi TI, serta menyetujui strategi yang selaras dengan hal tersebut.

- Penilaian dari keuntungan dan dampak yang akan terjadi dari perubahan potensial yang akan dilakukan pada model bisnis, model TI, kemampuan TI serta program investasi TI.

- Identifikasi resiko, biaya, dan dampak dari perubahan organisasi, evolusi teknologi, kebutuhan regulasi, reengineering proses bisnis, penempatan karyawan dalam merencanakan proses.

- Road map yang mengindikasikan penjadwalan dan kebergantungan dari rencana, serta mengubah tujuan menjadi hasil yang dapat diukur dengan representasi matriks.

B. $K G I$

KGI untuk APO 01

- $80 \%$ sasaran dan kebutuhan strategis organisasi didukung oleh sasaran strategis TI.

- $\quad 90 \%$ staf memiliki kemampuan TI yang sesuai dengan kompetensi yang diperlukan oleh perannya.

- $80 \%$ kebijakan didukung dengan standard dan praktek kerja yang efektif.

- Level kepuasan stakeholder terkait level keahlian dan ide inovasi TI.

KGI untuk APO 02

- $85 \%$ value driver TI dipetakan ke value driver bisnis

- $80 \%$ stakeholder puas dengan portofolio program dan layanan TI yang telah direncanakan.

- $80 \%$ pengguna puas dengan kualitas layanan TI yang disampaikan. 
C. $K P I$

KPI untuk APO 01

Page 69 - $90 \%$ kebijakan, standard dan enabler lainnya didokumentasikan dan diperbaharui terus menerus.

- $75 \%$ Jumlah staf menghadiri pelatihan atau sesi tentang implementasi kebijakan

KPI untuk APO 02

- $90 \%$ tujuan dalam strategi TI mendukung strategi organisasi.

- $90 \%$ portofolio proyek TI dapat secara langsung ditelusuri pada strategi TI.

- $70 \%$ tujuan strategis organisasi dicapai sebagai hasil strategi inisiatif TI

\section{KESIMPULAN}

Proses APO 01 dan APO 02 mencukupi untuk digunakan sebagai dasar penilaian tata kelola teknologi informasi khususnya dalam perencanaan strategi TI. Proses pemetaan proses Cobit 5 ke Cobit PAM dapat menghasilkan kerangka yang komponennya yaitu best practice dan work product dapat digunakan didalam penilaian tata kelola teknologi informasi. Penilaian tata kelola teknologi informasi berdasarkan kapabilitas proses menghasilkan akhir penilaian yang komprehensif. Tata kelola teknologi Universitas Tanjungpura berdasarkan level kapabilitas berada pada level 0 dikarenakan keseluruhan proses Cobit yang dinilai tidak memenuhi fully achieved. Pencapaian level tata kelola TI saat ini dapat memberikan gambaran tentang keadaan yang dihadapi organisasi saat ini mengenai proses TI nya dan dapat dijadikan sebagai dasar keputusan untuk perencanaan dimasa yang akan datang. Rekomendasi perbaikan proses yang disarankan kepada Universitas Tanjungpura dapat digunakan sebagai pedoman memperbaiki tata kelola teknologi informasi di lingkungan universitas.

\section{REFERENSI}

[1] ISO \& IEC. ISO/IEC 38500:2008 Corporate Governance of Information Technology. ISO/IEC, 2008.

[2] ISACA. Cobit 5: Enabling Process. ISACA, 2012.

[3] Doughty, K., \& Grieco, F. "IT Governance: Pass or Fail?" Journal Online Information Systems Audit and Control Association (ISACA), 2005.

[4] ISACA. Cobit 5: A Business Framework for the Governance and Management of Enterprise IT. ISACA, 2012.

[5] ITGI. Cobit 4.1: Framework, Control Objectives, Management Guidelines, Maturity Models. ITGI, 2007.

[6] Grembergen, Wim Van and De Haes, Steven. (2005) Cobit's Management Guidelines Revisited: The KGIs/KPIs Cascade. [Online]. Available: http://www.isaca.org

[7] ISACA. COBIT Process Assessment Model Using COBIT 4.1. ISACA, 2011. 